\title{
Redes sociais e ativismo materno: desafios entre estudantes de uma universidade pública
}

\author{
Maria Clara Ramos da Fonseca Silva ${ }^{1}$ \\ https://orcid.org/0000-0002-4864-1224
}

\author{
Cristiano Guedes ${ }^{2}$ \\ https://orcid.org/0000-0001-690826-04
}

${ }^{1}$ Universidade de Brasília, Faculdade de Ciências da Saúde, Programa de Pós-Graduação em Saúde Coletiva, Brasília, DF, Brasil

${ }^{2}$ Universidade de Brasília, Instituto de Ciências Humanas, Programa de Pós-Graduação em Política Social, Brasília, DF, Brasil

\section{Redes sociais e ativismo materno: desafios entre estudantes de uma universidade pública}

Resumo: As conquistas femininas das últimas décadas suscitam novas estratégias tanto para a manutenção dos direitos já garantidos quanto para a solução das demandas que se apresentam, a fim de promover a superação dos sistemas de dominação e exploração que acometem as mulheres e que são reproduzidos nos mais diversos espaços, como é o caso das instituições públicas de ensino superior. Tomando as construções sociais em torno do que se conhece como feminino e a centralidade da maternidade nesse contexto, este artigo analisa as condições de permanência de estudantes que são mães em uma universidade pública federal, por meio da realização de questionários virtuais e registros em diários de campo resultantes da participação em grupo virtual do aplicativo WhatsApp. Os resultados apontam para o protagonismo das estudantes nos processos reivindicatórios perante a desresponsabilização do poder público e o papel das redes sociais em sua organização política, por meio do chamado ciberativismo.

Palavras-chave: Maternidade. Universidade. Redes Sociais. Ciberativismo.

\section{Social networks and maternal activism: challenges faced by students from a public university}

Abstract: The female conquests over the last decades raise new strategies both to maintain guaranteed rights and to respond to upcoming demands in order to overcome the systems of domination and exploitation that affect women in the most diverse spaces, including public universities. Taking into consideration the social constructions around what is known as feminine and the centrality of motherhood in this context, this paper analyzes the conditions for the permanence of student mothers at a federal public university. Virtual questionnaires and records in field diaries resulting from the participation both in a WhatsApp group and a face-to-face group were used as research instruments. The results point to the students' protagonism in disputing the withdrawal of state responsibility, as well as the role of social networks in their political organization, through the so-called cyberactivism.

Keywords: Maternity. University. Social networks. Cyberactivism.

Recebido em 28.02.2020. Aprovado em 27.03.2020. Revisado em 10.06.2020.

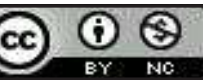

(C) O(s) Autor(es). 2020 Acesso Aberto Esta obra está licenciada sob os termos da Licença Creative Commons

Atribuição-NãoComercial 4.0 Internacional (https://creativecommons.org/licenses/by-nc/4.0/deed.pt_BR), que permite copiar, distribuir e reproduzir em qualquer meio, bem como adaptar, transformar e criar a partir deste material, desde que para fins não comerciais e que você forneça o devido crédito aos autores e a fonte, insira um link para a Licença Creative Commons e indique se mudanças foram feitas. 


\section{Introdução}

As redes sociais são cada vez mais utilizadas no mundo globalizado como meio para a reivindicação de direitos sociais e a participação política. No Brasil, a ascensão das redes sociais tem tido destaque e interferido no cenário político, como evidenciaram os movimentos de rua ocorridos em 2013, o processo de impeachment em 2016 e a ascensão ao poder, em 2018, de um governo brasileiro de extrema direita, ultraneoliberal, conservador e hábil no uso de redes sociais para a difusão de ideias contrárias à preservação de direitos universais. Analistas políticos do mundo contemporâneo concordam sobre o papel decisivo das redes sociais do mundo virtual em processos eleitorais e no exercício da política. O mundo virtual com suas redes sociais torna-se, portanto, um objeto de estudo a ser explorado criticamente nos processos de trabalho de assistentes sociais, sobretudo na disputa de narrativas sobre democracia, justiça social e acesso a direitos sociais.

$\mathrm{Na}$ literatura científica, é possível evidenciar algumas das repercussões do uso de redes sociais na sociedade brasileira. Os processos eleitorais podem ser apontados como foco privilegiado de análise sobre o poder das redes sociais e suas repercussões na democracia. Entretanto, estudos sobre redes sociais revelam também que esses meios virtuais têm tido relevo na organização, no planejamento e na divulgação de ações de movimentos sociais com suas pautas reivindicatórias. Entre os movimentos sociais que se utilizam das redes virtuais como espaços privilegiados para o ativismo está o ciberfeminismo, que, segundo Fabiana Martinez (2019, p. 7), consiste em "um movimento estético e político orientado pela popularização das tecnologias digitais que renovou o debate feminista, questionando as desigualdades de gênero através das relações das mulheres com a ciência, a tecnologia e a cultura eletrônica". O acesso ao mundo virtual com suas tecnologias foi marcado, sobretudo com o surgimento da Internet ao final dos anos 1990, pelo predomínio de homens, seja como usuários, seja como profissionais da informática (NATANSOHN, 2013). Por outro lado, a participação de mulheres e grupos historicamente discriminados no mundo virtual é crescente desde os anos 2000, com a popularização do acesso aos meios tecnológicos e o consequente uso desses meios para a reivindicação de direitos (CARVALHO, 2017; MARTINEZ, 2019; SENA; TESSER, 2017).

Este artigo analisa as condições de permanência no ensino superior de estudantes de graduação de uma universidade pública federal que são mães e cuidadoras de suas crianças. A pesquisa foi desenvolvida em redes sociais criadas por mulheres que desempenham o papel da maternidade paralelamente ao ofício de estudantes. Os dados foram coletados por meio de questionários eletrônicos e também pelo uso de registros em diários de campo resultantes da participação tanto em grupo virtual do aplicativo WhatsApp como em grupos presenciais de discussão criados por essas mulheres para o compartilhamento de suas experiências. A identidade das mulheres participantes foi mantida em sigilo. Foi aplicado um total de 38 questionários, e o projeto de pesquisa não foi submetido para a análise de um comitê de ética, visto se tratar de uma pesquisa de opinião pública com participantes não identificadas, em conformidade com a Resolução nº 510/2016 do Conselho Nacional de Saúde (2016).

\section{Maternidade: suposto dever sagrado}

A divisão racial e sexual do trabalho, que veio a predeterminar funções aos homens e às mulheres, é um conceito histórico e perpassado por construções sociais que demarcaram diferenças estruturais para além das causalidades biológicas (KERGOAT, 2009). Essa divisão engendrou-se na dinâmica de diversas sociedades de tal forma que tais funções e papéis, fortemente baseados nas desigualdades de gênero, assumiram centralidade no desenvolvimento da dominação capitalista, patriarcal e sexista. Entende-se, ainda, ser imprescindível compreender este processo associado às categorias de raça e classe que, segundo Heleieth Saffioti (1987), constituem sistemas de dominação-exploração que não podem ser apreendidos isoladamente. Gênero, raça e classe, portanto, constituem determinantes estruturais fundamentais à manutenção das relações de poder, dominação e exploração estabelecidas ao longo da história (HIRATA, 2014).

Pode-se dizer, com isto, que a maternidade acomete as mulheres de diferentes formas, apesar dos padrões construídos histórica e socialmente (SCAVONE, 2001). Pautada por modelos que se transformam a partir das especificidades locais e temporais, mas alcançam as mulheres em diferentes momentos históricos (BADINTER, 2011), ela tem papel de destaque principalmente por atribuir à mulher a responsabilidade primeira pelas práticas de cuidado com os filhos e as filhas, a família e a casa, ou seja, as atividades domésticas (GUEDES, 2016).

A despeito disso, e para além da padronização a respeito dos comportamentos relacionados ao modus operandi de ser mulher e mãe, houve significativas transformações sociais e conquistas alcançadas pelos movimentos feministas e de mulheres por espaços na vida pública, como as universidades e o mercado de 
trabalho formal. Esses processos foram marcados - e continuam a ser - por profundas contradições, expressas, sobretudo, nas exigências feitas pelo conjunto da sociedade às mulheres: espera-se que estas sejam mães ao mesmo tempo em que são conquistadas e/ou lhes são concedidas novas oportunidades. As mulheres passam a ocupar diversos lugares, alguns de suma importância para a economia e o controle do Estado, mas não são pensadas nem oferecidas as condições necessárias para que possam vivenciar a maternidade e as aspirações profissionais, pessoais e de lazer sem, contudo, abrir mão destas últimas.

Por outro lado, ao revés, agarrada às concepções tradicionais sobre a função materna - naturalizada e socialmente construída na sociedade brasileira, que é patriarcal e majoritariamente sexista -, a sociedade, a partir das transformações econômicas e políticas em curso, está a colocar as mulheres de volta ao mundo particular. Ou seja, a partir do discurso naturalista, oportunamente apreendido sob uma ótica conservadora (BADINTER, 2011), mesmo as mulheres que já alcançaram algum nível de igualdade de oportunidades em relação aos homens estão, mais uma vez, relegadas ao universo doméstico, agora sob a roupagem associada ao instinto materno. Isto é, espera-se que a mulher seja mãe e o seja exclusivamente, uma vez que seu lugar é reservado, social, política e economicamente, à esfera doméstica e privada.

Desta feita, a conciliação entre a vida acadêmica e profissional e as exigências próprias da maternidade - estas compreendidas, sob a ótica do senso comum, como consequências das escolhas pessoais das mulheres, sejam elas tomadas com liberdade ou não - tem relação direta com o contexto social, econômico, político e cultural, em âmbito individual e coletivo. É nesse compasso que a criação de condições para tornar possível a vivência, em concomitância, da maternidade e da vida acadêmica tende a recair sobre o discurso da individualização e culpabilização, dada a noção equivocada de que esta seria a principal responsável pelo sucesso ou fracasso materno e profissional. Outrossim, é comum que as mulheres se questionem sobre as reais possibilidades de conciliar as aspirações pessoais e os deveres de mãe. Contudo, se para algumas existem tais questionamentos, para outras, não há alternativas. Sobre isto, Gama (2012) aponta que o trabalho e o Estado não se apresentam da mesma forma nem tampouco impactam igualmente a organização da reprodução social para o conjunto dos grupos socioeconômicos, em especial as mulheres.

Isso significa que o ideal socialmente construído - que,

\section{Desta feita, a conciliação entre} a vida acadêmica $\mathrm{e}$ profissional e as exigências próprias da maternidade estas compreendidas, sob a ótica do senso comum, como consequências das escolhas

pessoais das mulheres, sejam elas tomadas com liberdade ou não - tem relação direta com o contexto social, econômico, político e cultural, em âmbito individual e coletivo. vale destacar, é mutável ao longo da história, a depender de aspectos territoriais, culturais, políticos, econômicos e sociais - em torno da boa mãe, trazendo a mulher de volta ao lar, é "inacessível a inúmeras mulheres", mas "pelo menos se impôs, nas mentes e nas práticas" (BADINTER, 2011, p. 134). Isto é, sendo um dos pilares do desenvolvimento do modo de produção capitalista, a conquista, em parte, de espaços e postos na esfera pública por mulheres não as desonera de toda a carga e obrigação imposta com relação ao trabalho de cuidados na esfera doméstica - este, por sua vez, não remunerado, desvalorizado e invisível (DANIEL, 2011).

Em vista de um processo de industrialização e urbanização que ganha força em meados do século XX (CISNE; SANTOS, 2018) e a partir das lutas engendradas pelas próprias mulheres em conjunto com a sociedade, o governo reconheceu a necessidade de acesso à educação pela população feminina. Esta educação, todavia, não visava a um alcance amplo das mulheres, mas somente daquelas de classes mais altas, em sua maioria, brancas. A Pesquisa Nacional por Amostra de Domicílios Contínua (PNAD Contínua) realizada pelo Instituto Brasileiro de Geografia e Estatística (IBGE) em 2016 revela que as mulheres possuem níveis de instrução superiores aos dos homens: $21,5 \%$ delas possuem ensino superior contra $15,6 \%$ deles. Há, todavia, uma latente desigualdade entre as próprias mulheres, dado que $23,5 \%$ das brancas têm ensino superior completo contra somente $10,4 \%$ das pretas e pardas, número inferior ao percentual de homens brancos $(20,7 \%)$ (INSTITUTO BRASILEIRO DE GEOGRAFIA E ESTATÍSTICA, 2018).

A partir do exposto, em vias de um processo de acirramento do neoliberalismo e com o avanço do conservadorismo no Brasil, infere-se que as políticas públicas e sociais, especialmente aquelas diretamente relacionadas a grupos populacionais historicamente discriminados, como mulheres, negros, negras e povos e 
comunidades tradicionais, sofrerão constantes tentativas de sucateamento e desmontes a partir da redução de recursos destinados especialmente à área social, além da transferência - já em curso - da primazia da responsabilidade estatal para a sociedade civil. Nesse sentido, a responsabilidade do Estado perante as demandas relacionadas à maternidade e à infância tem sido ameaçada (YANNOULAS, 2003).

Esse cenário é agravado quando se trata de estudantes que são mães, trabalhadoras e cuidadoras - aqui, a categoria cuidadora se aplica às estudantes que são mães devido à associação entre cuidado e feminilidade na sociedade brasileira. $\mathrm{O}$ acesso à universidade, embora também configure uma importante conquista feminina ao longo de uma história de privações, negligências e subordinação, é fruto de uma relação contraditória entre possibilidades e limites do ser mulher no espaço acadêmico. Isto porque, nas palavras de Marilena Chauí (2003, p. 5), "a universidade é uma instituição social e como tal exprime de maneira determinada a estrutura e o modo de funcionamento da sociedade como um todo". Portanto, as relações desiguais de gênero, classe, raça e etnia continuam a caracterizar e condicionar a presença da mulher no ensino superior (ASSUMPÇÃO, 2014).

Isso significa que a maternidade é marcada por contradições e desigualdades, uma vez que o acesso à universidade por homens que possuem filhos ou filhas é privilegiado, se comparado à situação de estudantes universitárias que são mães (SAMPAIO, 2011). Isso se deve, sobretudo, aos estratégicos construtos sociais baseados em distinções arcaicas sobre o que corresponde aos universos masculino e feminino, a fim de garantir a manutenção do sistema econômico e político vigente. Imprime-se, assim, à presença feminina no espaço acadêmico forte influência das obrigações domésticas associadas às mulheres, o que justifica, parcialmente, o elevado índice de mulheres em determinados cursos (CEGATTI; PRÁ, 2016).

A pesquisa relatada neste artigo foi feita por meio de redes sociais virtuais e teve como objetivo analisar de que forma a maternidade repercute na vivência acadêmica de graduandas que são mães, bem como evidenciar se as relações desiguais de gênero influenciam a realização da graduação por essas estudantes. Os resultados mostram a situação de desigualdade vivenciada por mulheres mães na graduação e o potencial da Internet para dar visibilidade às suas frágeis condições de permanência na universidade e suas pautas reivindicatórias. A articulação entre maternidade e vida acadêmica ainda é um desafio para as participantes da pesquisa, principalmente por conta da sobrecarga de trabalho no exercício da maternidade e das discriminações e desigualdades. Os dados deste estudo provocam a reflexão sobre as possibilidades do impacto das redes sociais virtuais na organização de estudantes mães e os desafios epistemológicos de pesquisas acadêmicas em e sobre redes sociais, um espaço tanto de obtenção de dados como de participação política.

\section{As estudantes mães participantes da pesquisa e da rede social de apoio}

Esta pesquisa trouxe como primeira contribuição mostrar o perfil das estudantes de graduação com filhos, uma informação pouco considerada ou mesmo ignorada nos registros oficiais da universidade, embora fundamental para o entendimento das condições de permanência e êxito acadêmico desse grupo de mulheres no ensino superior. São mulheres entre 19 e 33 anos, a maioria pertencente à faixa etária de 21 a 25 anos, graduandas de dezesseis cursos em diferentes áreas. Majoritariamente, são mulheres brancas (40,7\%), tendo $37 \%$ se declarado negras e 18,5\% pardas, com base na categorização atual feita pelo IBGE (2018). Entre as participantes, o índice de desemprego é elevado, e a maior parte daquelas que declararam estar empregadas não têm carteira assinada. Outro desafio enfrentado por essas mulheres é o acesso ao campus universitário central, visto que residem em regiões periféricas e distantes, o que pode contribuir para ausência ou atrasos nas aulas em razão dos compromissos do cuidado de suas crianças.

Os vínculos afetivos das mulheres é outro aspecto relevante para entender seus contextos relacionais. Quase metade delas estão namorando (44,4\%), enquanto 37\% são casadas e 14,8\% estão solteiras. Há, também, aquelas consideradas chefes de famílias monoparentais. No Brasil, de acordo com a PNAD/IBGE (2018), as famílias monoparentais chefiadas por mulheres cresceram de 9 milhões em 2001 para 11,6 milhões em 2015. Aline Santos afirma que, desde as décadas de 1980 e 1990, o Brasil tem passado por profundas mudanças econômicas e sociais que refletiram nas estruturas familiares até então hegemônicas. Nas palavras da autora, isto se deve principalmente "à redução dos níveis de fecundidade da população, às lutas sociais pela igualdade entre homens e mulheres, ao incremento da força de trabalho feminina e ao surgimento de novos formatos de família" (SANTOS, 2008, p. 2).

O percentual de mulheres mães nas universidades brasileiras demanda ações do Estado. As políticas públicas na Educação necessitam adotar novas práticas sociais de cuidado no ensino para não corroborar e reproduzir práticas discriminatórias. O desafio está em romper com fatores que favoreçam a evasão de mulheres do ensino superior e dificuldades futuras de inserção no mercado de trabalho. No caso das estudantes mães participantes da rede social neste estudo, observou-se que essas mulheres, apesar de possuírem companheiros, 
tendem a assumir solitariamente o cuidado de suas crianças e demais trabalhos domésticos, sendo este um obstáculo ao êxito acadêmico no contexto de uma universidade pública ainda alheia às necessidades do ofício da maternidade de parte de sua comunidade.

\section{Maternidade e vida acadêmica: principais desafios}

Entre as principais dificuldades vivenciadas pelas participantes para continuar sua formação acadêmica, à parte as particularidades de cada uma, pode-se eleger um ponto comum que culmina no acirramento, em menor ou maior grau, das desigualdades que elas experimentam: a sobrecarga de trabalho materno e a consequente falta de recursos para as atividades de formação universitária. Com base no entendimento de Marcondes e Yannoulas (2012) sobre o cuidado, considerado como estar à disposição, e a partir da responsabilização materna, concomitante à desresponsabilização paterna e à dificuldade imposta pela comunidade acadêmica e pelo poder público, grande parte das participantes está condicionada a uma sobrecarga, que pode ser física e/ou emocional/psíquica, determinante à dinâmica acadêmica.

Constatou-se que a maior parte das participantes são as principais responsáveis pelo cuidado com seus filhos e/ou filhas, limitando, assim, o tempo destinado à presença em sala de aula e à rotina de estudos. Com base nos dados obtidos, os desafios à permanência de estudantes que são mães e cuidadoras na universidade na conciliação entre maternidade e vida acadêmica são: dificuldade em solicitar regime de exercícios domiciliares; baixo acesso a creches públicas e ausência de condições econômicas para buscar tal serviço na rede privada; dificuldade em acompanhar o fluxo dos respectivos cursos; resistência por parte de docentes às estudantes que necessitam levar sua criança à sala de aula; incompreensão, pelos docentes, da sobrecarga de atividades e do número de ausências; discriminações praticadas pela comunidade acadêmica, sobretudo os discentes; ausência de salas acessíveis destinadas à amamentação e a cuidados básicos (algumas estudantes relataram realizar a troca de fraldas em carrinhos, bancos e mesas nos corredores); ausência afetiva e/ou financeira por parte dos genitores; ausência de rede de apoio; distância entre a residência e a universidade; gravidez de risco; perseguição paterna; depressão pós-parto; trancamento do semestre em decorrência da sobrecarga; e impossibilidade de conciliar o puerpério e as atividades acadêmicas.

Diante desses fatores, $78,4 \%$ das participantes afirmaram ter realizado alguma interrupção no curso em decorrência da gestação e/ou da maternidade, enquanto $62,2 \%$ disseram conhecer alguma estudante que abandonou o curso em decorrência da maternidade. Ademais, a dificuldade em acessar políticas como transporte, moradia e saúde pública surgiu como limitador ao desempenho acadêmico e trabalho materno. O grupo de WhatsApp acompanhado neste estudo se converteu em um canal de desabafo para o compartilhamento de opressões vivenciadas no ofício da maternidade e de questionamentos das regras universitárias insensíveis às peculiaridades da maternidade, como revelam outras pesquisas, em que mulheres utilizaram redes sociais para denunciar violências (SENA; TESSER, 2017).

\section{Estratégias e possibilidades: a difícil conciliação dos papéis de mãe e estudante}

No Brasil, a Lei ${ }^{\circ}$ 6.202, de 17 de abril de 1975, garante à estudante gestante, a partir do oitavo mês e durante três meses, a possibilidade de dar continuidade aos estudos por regime de exercícios domiciliares, mediante apresentação de atestado médico (BRASIL, 1975). Em casos excepcionais, há a possibilidade de extensão desse tempo. Esta é a única política pública assegurada por lei às estudantes gestantes de instituições federais de ensino superior no país. De todo modo, as alunas que possuem interesse em dar entrada ao regime de exercícios domiciliares estão suscetíveis ao cumprimento das exigências feitas pelos departamentos dos cursos e seus respectivos docentes. Enquanto algumas estudantes relataram ter tido apoio dos docentes, outras reclamaram da demora no processo de pedido de regime domiciliar e no repasse do requerimento pelo departamento aos docentes, além da incompletude das informações oferecidas por técnicos do setor responsável pelo atendimento de estudantes mães solicitantes de direitos previstos nas normatizações institucionais. De toda sorte, mesmo entre aquelas que conseguiram aprovação do pedido, o intenso fluxo de atividades e as exigências da maternidade ocasionaram o trancamento do semestre letivo.

$\mathrm{Na}$ instituição em que ocorreu a pesquisa, as estudantes de graduação que são mães contam com algumas estratégias para dar continuidade à sua formação, tais como a divisão do cuidado com familiares e amigos ou amigas durante os períodos de aula, o acesso a creches e escolas públicas e/ou particulares, o programa de assistência estudantil, o serviço de babás e, em alguns casos, o recurso de levar a criança para a sala de aula. Estas estratégias, todavia, não alcançam o conjunto das estudantes mães, especialmente aquelas 
que necessitam levar a criança para a universidade, tendo em vista a dificuldade de locomoção, a discriminação de docentes e discentes e a ausência de estruturas para cuidados básicos, como fraldários e chuveiros.

O Programa Infanto-Juvenil (PIJ), criado em 1983, é um projeto que atende crianças de 2 a 9 anos, filhos ou filhas de servidores e servidoras de uma associação ligada à universidade, de estudantes e docentes e da comunidade externa, mediante valor pago a depender da quantidade de dias e do público-alvo: associados, estudantes, docentes ou comunidade externa. No PIJ, são realizadas atividades lúdicas, educativas e recreativas no contraturno escolar, ou seja, não se trata de uma creche ou escola formal. Apesar de ser bem estruturado e ter uma proposta pedagógica que visa compreender a criança como sujeito autônomo e criativo, esse espaço não contempla o conjunto das estudantes de baixa renda, devido ao valor cobrado, nem tampouco as estudantes mães de crianças com idade inferior a 2 anos (ASSOCIAÇÃO DOS SERVIDORES DA FUNDAÇÃO UNIVERSIDADE DE BRASÍLIA, [2017]).

Em 2017, o Decanato de Assuntos Comunitários da universidade lançou o primeiro edital do Programa Auxílio Creche (PACreche), que consiste na concessão de auxílio financeiro a estudantes em situação de vulnerabilidade que sejam responsáveis legais e residam com crianças entre 0 e 5 anos incompletos ainda não contempladas com vaga em creche ou pré-escola na rede pública de ensino (TORRES, 2017). Todavia, o número de bolsas ofertadas é insuficiente - comumente, desde o início do programa, são ofertadas 10, contudo, conforme o último edital de seleção, referente ao segundo semestre letivo de 2019, não houve nenhuma bolsa disponível. Isso significa que parcela considerável de estudantes mães e pais não foi contemplada pelo programa. A ampliação do número de bolsas para acesso aos programas de assistência estudantil é uma das exigências feitas pelas participantes da pesquisa.

Em 2018, foi criado um espaço de acolhimento para estudantes regulares, servidores técnicos e docentes da Faculdade de Educação (FE) que sejam mães e/ou pais de crianças de 0 a 12 anos incompletos. Nesse espaço, as crianças devem permanecer na companhia de seus responsáveis. A sala pode ser utilizada, em tese, de segunda a sexta feira, das $7 \mathrm{~h} 30$ às $22 \mathrm{~h} 40$, e conta com brinquedos, trocadores, mesas, cadeiras, microondas, refrigerador, computador e um banheiro adaptado para crianças. Contudo, conforme a Resolução $\mathrm{n}^{\circ}$ 001/2018, do Conselho da FE, o acesso é limitado (UNIVERSIDADE DE BRASÍLIA, 2018). Além de estar disponível apenas a estudantes, servidores e servidoras e docentes da Faculdade de Educação, é necessária a realização de um cadastro na Assessoria Pedagógica da FE, e o acesso às chaves é feito mediante apresentação de carteirinha de identificação. Segundo relatos compartilhados por meio de rede social e conversas presenciais, embora seja uma inciativa importante no reconhecimento das necessidades das estudantes, essa sala necessita ser aperfeiçoada em alguns aspectos, como as condições de limpeza e a ampliação do acesso, que não se estende às mulheres de outros cursos, que possuem as mesmas necessidades de assistência.

Recentemente, ao final de 2019, foi criada uma rede virtual de estudantes mães e voluntárias com vistas a reduzir os índices de evasão entre graduandas que são mães. A Rede Voluntária de Apoio Infantil para Permanência Universitária (Rede VOA) tem como objetivo possibilitar a criação de um espaço físico para acolhimento de crianças entre 6 meses e 6 anos, nos períodos de aula de suas responsáveis na universidade, sobretudo daquelas estudantes que detêm a maior parte da responsabilidade de cuidados com a criança, não contam com rede de apoio, não foram beneficiadas com vaga na rede de creches públicas do DF nem tampouco têm meios suficientes para buscar tal serviço na rede particular. Apenas 38,9\% das participantes deste estudo dispõem de creches para suas crianças e, destas, somente 38,5\% estão na rede pública. Em contrapartida, 83,8\% das participantes concordam com a necessidade da criação de creches gratuitas para os filhos e filhas das estudantes.

Para as participantes da pesquisa, a fim de reduzir as barreiras que dificultam e/ou impedem a conclusão do curso, enquanto mães, cuidadoras, trabalhadoras e universitárias, é urgente a adoção de algumas medidas, especialmente por parte da universidade, como a criação e destinação de sala específica para amamentação e cuidados básicos com as crianças, com condições de limpeza adequadas e disponível a estudantes de todos os cursos; a flexibilidade nos horários das aulas; a preferência/prioridade na matrícula em disciplinas; a sensibilização da comunidade acadêmica, por meio de ações que promovam o respeito às estudantes e às crianças; debates acerca das condições das estudantes mães e cuidadoras, a fim de propor novas estratégias; a instalação de fraldários; a criação de um sistema de dados que verifique e acompanhe a permanência de estudantes mães; o desconto no valor das mensalidades para estudantes no PIJ; e a desburocratização do processo de trancamento justificado.

Os mecanismos e as iniciativas existentes na instituição em que foi realizada a pesquisa são fruto de mobilizações presenciais, com auxílio das redes sociais, por meio das quais as estudantes de graduação, com o apoio de parte da comunidade universitária, buscam reduzir os obstáculos à permanência e à conclusão de seus estudos em um ambiente ainda pouco sensível ou até hostil às necessidades de mulheres que, além de graduandas, exercem o ofício de cuidadoras de suas crianças. Todavia, embora importantes, tais iniciativas podem ser consideradas insuficientes, e as estudantes esperam uma política estrutural da universidade que atenda a todas as mães graduandas indistintamente, para além de iniciativas pulverizadas e restritas a algumas unidades acadêmicas. 


\section{Possibilidades da luta no mundo virtual: entre redes sociais e redes sociais virtuais}

A importância da articulação em redes sociais entre as discentes revela não somente a socialização de problemas e situações em comum, com uma consequente organização para a exigência de soluções e garantias institucionais e governamentais, mas sobretudo a construção de redes de apoio a fim de buscar soluções alternativas, dada a urgência das demandas postas. Além disso, os aplicativos onde se materializam as relações virtuais em rede servem como canais importantes de comunicação e compartilhamento de informações (SENA; TESSER, 2017) relativas aos mais diversos assuntos, como maternidade, universidade, política, lazer, sexualidade e saúde, em um movimento de ativismo online ou no espaço virtual que acontece "através da troca e da discussão de conteúdos" (MARTINEZ, 2019, p. 6). Complementarmente, "essa possibilidade de troca que as novas tecnologias de comunicação favoreceram e impulsionaram, mostraram, na prática, a possibilidade de fortalecimento das lutas por meio do ciberativismo" (SENA; TESSER, 2017, p. 210). Neste estudo, a Internet assume então dupla relevância: como local de pesquisa - não exclusivamente, mas em considerável parte do processo de coleta de dados - e como instrumento determinante para o desenvolvimento de pesquisa (FRAGOSO, 2011).

Isto posto, as redes sociais virtuais e o uso da Internet para mobilização podem ser alçados à categoria de destaque entre os resultados desta investigação, tanto como ferramenta privilegiada de obtenção de informações quanto como ferramenta metodológica. A partir das análises realizadas, as redes sociais e as redes sociais virtuais, apreendidas em um contexto macroestrutural das determinações sociais, econômicas e políticas, são os principais meios de requerer a atenção institucional e, consequentemente, governamental no que tange à criação, consolidação e efetivação de meios para a permanência na universidade pelas estudantes participantes. Embora não se trate de um movimento essencialmente feminista - ainda que muitas estudantes assim se reivindiquem - em suas mais diversas expressões, mas muito mais uma organização e um compartilhamento de pautas entre mulheres, o uso de um aplicativo para tratar sobre tais questões resultou em terreno fértil para a construção de uma rede social virtual, alimentada por redes sociais anteriores e pelas emergentes após a criação do grupo.

Nesse momento, a internet começa a ocupar um papel muito semelhante ao dos grupos de consciência nos Estados Unidos na década de 70, se consolidando como um espaço facilitador de trocas, onde as mulheres (mesmo as que não reivindicam para si uma identidade feminista) identificam, compartilham e nomeiam experiências comuns (MARTINEZ, 2019, p. 11).

Este cenário indica, de imediato, o nível de autonomia e a capacidade de inter-relação entre essas mulheres, a relevância social das redes e seu caráter organizativo, político e de lutas - culminando em uma espécie de movimento social. Por outro lado e contraditoriamente, sugere reflexões a respeito da responsabilização das mulheres que são mães na concretização do acesso ao ensino superior, sobretudo no que tange a questões que extrapolam os limites pessoais e estão diretamente relacionadas às decisões estatais e institucionais, como a oferta de creches, a criação de espaços de acolhimento e cuidados com as crianças e, em um nível mais abrangente, o combate às desigualdades de gênero, classe, raça e etnia.

\section{Considerações Finais}

Ao conjunto das estudantes que participaram da pesquisa, é difícil vivenciar, concomitantemente, maternidade e vida acadêmica. A universidade pública carece de ações voltadas ao atendimento de estudantes de graduação com filhos ou filhas, e a mesma postura se observa na falta de atenção às demandas de tais estudantes por suas respectivas unidades acadêmicas, docentes e servidores, que, por vezes, têm se mostrado omissos ou negligentes. Este estudo mostrou como a Internet e suas redes sociais representam uma estratégia de participação política alternativa para estudantes mães cuja sobrecarga de trabalho e responsabilizações sexistas, historicamente construídas na sociedade patriarcal brasileira, impediriam a reivindicação de seus direitos no ensino superior.

A guinada conservadora na cena política contemporânea e o fortalecimento do paradigma neoliberal no Brasil também impõem consideráveis retrocessos às políticas públicas e sociais, uma vez que, retomado e fortalecido o modelo do familismo, são enfraquecidas a noção de direito e a destinação de recursos e investimentos a áreas estratégicas no combate às desigualdades de diversas ordens, favorecendo-se, a contrapelo, os processos de terceirização e privatização dos serviços públicos. Isto se torna evidente, a título de exemplo, com os recentes ataques e cortes de bolsas nas instituições de ensino superior, que podem impactar de forma negativa o alcance dos programas de assistência estudantil, agudizar o sucateamento dos serviços, programas 
e ações ofertadas pelas políticas de assistência social e saúde, radicalizar o desmonte da política de previdência social e intensificar a precarização da política de educação. Tudo isso reforça as desigualdades de oportunidades entre homens e mulheres, bem como entre mulheres brancas e mulheres negras e, indubitavelmente, tornam ainda mais complexas as relações estabelecidas em torno da maternidade, prejudicando a trajetória acadêmica de estudantes mães e cuidadoras.

Nota-se, nesse cenário, o incentivo à maternidade como função natural de toda mulher e, ao mesmo tempo, a desvalorização das mulheres que são mães, estas deslegitimadas enquanto sujeitas ativas e capazes de desempenhar funções e desenvolver novas habilidades além das que lhes foram previamente estabelecidas. No contexto das reflexões emergidas da própria pesquisa, isto significa que os espaços ditos públicos, de modo geral, são encarados como antagônicos a mulheres mães e suas crianças e, portanto, não se mostram acolhedores tanto em termos de infraestrutura quanto das ações humanas. Decerto, há uma relação contraditória em voga: o não reconhecimento social (e humano) da mulher mãe como participante da vida coletiva e constantemente afetada pelas transformações sociais e a necessidade desse não reconhecimento para a manutenção das relações de poder cimentadas na sociedade.

Por conseguinte, o ideal materno está em constante conflito com as exigências do mundo dos estudos e do trabalho. Mesmo as mulheres que são mães e optam por romper com a imposição hegemônica de um modelo materno estão suscetíveis às desigualdades já postas: um homem com filhos dificilmente enfrentará os mesmos obstáculos que uma mulher com filhos, especialmente se forem associados a isto determinantes como as questões raciais, a pobreza, a dificuldade de acesso a bens e serviços públicos e a maternidade solo. Por isso a importância de ações que visem combater a invisibilidade de estudantes mães e suas respectivas necessidades nas universidades, destacadamente por meio da inclusão, nos regimentos internos e nos programas assistenciais das instituições, de tópicos que deem sustentação, materialidade e status de direitos às manifestações e reivindicações feitas.

A despeito da naturalização da maternidade na vida das mulheres, é imperativa a organização e atuação da sociedade na luta contra as opressões de gênero, raça/etnia e classe. Apesar da importância das frágeis conquistas históricas já alcançadas pelas mulheres brasileiras, especialmente aquelas relativas ao direito à educação e ao trabalho, somente será possível assistir a uma emancipação humana, radical e plena das mulheres, em todas as suas particularidades, a partir da superação da ordem econômica capitalista e das desigualdades de raça/etnia e gênero, sistemas de dominação-exploração sustentados, sobretudo no Brasil, por uma mentalidade ainda colonial, racista, patriarcal e clientelista, que incide fortemente na organização das políticas e do Estado.

\section{Referências}

ASSOCIAÇÃO DOS SERVIDORES DA FUNDAÇÃO UNIVERSIDADE DE BRASÍLIA (ASFUB). Programa Infanto-Juvenil. Brasília, [2017]. Disponível em: https://asfub.org.br/historia/. Acesso em: 14 maio 2020.

ASSUMPÇÃO, A. S. B. M. A mulher no ensino superior: distribuição e representatividade. Cadernos do GEA, FLACSO, n. 6, jul./dez. 2014.

BADINTER, E. O conflito: a mulher e a mãe. Tradução: Vera Lúcia dos Reis. Rio de Janeiro: Record, 2011.

BRASIL. Presidência da República. Lei no 6.202, de 17 de abril de 1975. Atribui a estudante em estado de gestação o regime de exercícios domiciliares instituído pelo Decreto-Lei no 1.044, de 1969, e dá outras providências. Brasília, 1975. Disponível em: https:// www2.camara.leg.br/legin/fed/lei/1970-1979/lei-6202-17-abril-1975-357541-publicacaooriginal-1-pl.html. Acesso em: 14 maio 2020. CARVALHO, M. F. L. Nossa esperança é ciborgue? Subalternidade, reconhecimento e "tretas" na Internet. Revista Estudos Feministas, Florianópolis, v. 25, n. 1, p. 347-363, jan./abr. 2017.

CEGATTI, A. C.; PRÁ, J. R. Gênero, educação das mulheres e feminização do magistério no ensino básico. Revista Retratos da Escola, Brasília, v. 10, n. 18, p. 215-228, jan./jun. 2016.

CHAUÍ, M. A universidade sob nova perspectiva. Revista Brasileira de Educação, n. 24, p. 5-15, set./dez. 2003.

CISNE, M.; SANTOS, S. M. Feminismo, diversidade sexual e serviço social. São Paulo: Cortez, 2018.

CONSELHO NACIONAL DE SAÚDE (CNS). Resolução no 510, de 7 de abril de 2016. Brasília: Ministério da Saúde, abr. 2016. Disponível em: http://www.in.gov.br/materia/-/asset_publisher/Kujrw0TZC2Mb/content/id/22917581. Acesso em: 14 maio 2020.

DANIEL, C. O trabalho e a questão de gênero: a participação de mulheres na dinâmica do trabalho. O Social em Questão, ano XIV, n. 25-26, p. 323-344, 2011.

FRAGOSO, S. Métodos de pesquisa para Internet. Porto Alegre: Sulina, 2011.

GAMA, A. S. O conflito entre trabalho e responsabilidades familiares no Brasil: reflexões sobre os direitos do trabalho e a Política de Educação Infantil. 2012. 245f. Tese (Doutorado em Ciências-Saúde Pública) - Fundação Oswaldo Cruz, Rio de Janeiro, 2012.

GUEDES, C. Itinerários do cuidar em doenças falciformes e suas repercussões na vida de mulheres. Textos \& Contextos, Porto Alegre, v. 15 , n. 2, p. 370-381, ago./dez. 2016. 
HIRATA, H. Gênero, classe e raça: interseccionalidade e consubstancialidade das relações sociais. Tempo Social, São Paulo, v. 26, n. 1, p. 61-73, jan./jun. 2014.

INSTITUTO BRASILEIRO DE GEOGRAFIA E ESTATÍSTICA(IBGE). Estatísticas de gênero: indicadores sociais das mulheres no Brasil. Rio de Janeiro, 2018.

KERGOAT, D. Divisão sexual do trabalho e relações sociais de sexo. In: HIRATA, H. et al. (org.). Dicionário crítico do feminismo. São Paulo: Unesp, 2009. p. 67-75.

MARCONDES, M. M.; YANNOULAS, S. C. Práticas sociais de cuidado e a responsabilidade do Estado. Revista Ártemis, Paraíba, v. 13, p. 174-186, jan./jul. 2012.

MARTINEZ, F. Feminismos em movimento no ciberespaço. Cadernos Pagu, Campinas, n. 56, p. 1-34, 2019.

NATANSOHN, G. Qué têm a ver as tecnologías digitais com o gênero? In: (org.). Internet em código feminino: teorias e práticas.

Buenos Aires: La Crujía, 2013. p. 15-38.

SAFFIOTI, H. I. B. O poder do macho. São Paulo: Moderna, 1987.

SAMPAIO, S. M. R. (org.). Observatório da vida estudantil: primeiros estudos. Salvador: EDUFBA, 2011.

SANTOS, A. T. Famílias chefiadas por mulheres: permanências e rupturas com as tradicionais concepções de gênero. In: SEMINÁRIO INTERNACIONAL FAZENDO GÊNERO, 8., ago. Florianópolis, 2008. Anais... Florianópolis: UFSC, 2008.

SCAVONE, L. Maternidade: transformações na família e nas relações de gênero. Interface - Comunicação, Saúde, Educação, v. 5, n. 8, p. 47-60, fev. 2001.

SENA, L. M.; TESSER, C. D. Violência obstétrica no Brasil e o ciberativismo de mulheres mães: relato de duas experiências. Interface, Botucatu, v. 21, n. 60, p. 209-220, mar. 2017.

TORRES, T. Auxílio-creche para alunos da UnB com filho menor de quatro anos. UnB Notícias, Brasília, ago. 2017. Disponível em: https://noticias.unb.br/76-institucional/1720-auxilio-creche-para-aluno-da-unb-com-filhos-menores-de-quatro-anos. Acesso em: 13 maio 2020.

UNIVERSIDADE DE BRASÍLIA. Conselho da Faculdade de Educação (CFE). Resolução no 01/2018. Regulamenta o uso do Espaço de Acolhimento/Fraldário da Faculdade de Educação da Universidade de Brasília por mães, pais ou pessoas legal e/ou judicialmente responsáveis por crianças (os filhos ou dependentes de estudantes regulares, de servidores técnicos e de professores da FE/UnB). Brasília, 2018. Disponível em: http://www.noticias.unb.br/images/Noticias/Docs/Resoluo-001-2018_Sala-de-acolhimento.FE.PDF.

YANNOULAS, S. C. A convidada de pedra: mulheres e políticas públicas de trabalho e renda: entre a descentralização e a integração supranacional: um olhar a partir do Brasil (1988-2002). Brasília: FLACSO; Abaré, 2003.

\section{Maria Clara Ramos da Fonseca Silva}

miliclarar@gmail.com

Graduada em Serviço Social pela Universidade de Brasília (UnB)

Mestranda do Programa de Pós-Graduação em Saúde Coletiva da Universidade de Brasília (UnB)

\section{UnB}

Campus Universitário Darcy Ribeiro

Asa Norte, Brasília - DF

CEP: 70910-900

\section{Cristiano Guedes}

c.bsb.br@gmail.com

Doutor em Ciências da Saúde pela Universidade de Brasília (UnB)

Professor Associado do Programa de Pós-graduação em Política Social da Universidade de Brasília (UnB)

\section{Endereço}

Caixa Postal 2175

Brasília - DF

CEP: 70343-970

\section{Agradecimentos}

Agradecemos às mulheres que aceitaram participar da pesquisa virtual, ao CNPq pelo financiamento do projeto e à Universidade de Brasília pelo apoio financeiro e institucional por meio do Programa de Iniciação Científica Edital 2018/2019. Nossa gratidão também à equipe de avaliação interna e externa, que incenti- 
vou a redação deste artigo por meio de menção honrosa concedida para este trabalho durante $\mathrm{o} 25^{\circ}$ Congresso de Iniciação Científica, realizado entre 20 e 27 de dezembro de 2019 na Universidade de Brasília.

\section{Agência financiadora}

Não se aplica.

\section{Contribuições das autoras}

Maria Clara Ramos da Fonseca Silva foi responsável pelo trabalho de campo, pela análise dos dados e pela redação dos diários de campo e do artigo. Cristiano Guedes foi o orientador da pesquisa e coautor na redação do artigo.
Aprovação por Comitê de Ética e consentimento para participação

Não se aplica.

Consentimento para publicação

Consentimento dos autores.

\section{Conflito de interesses}

Não há conflito de interesses. 